\title{
Rejection Sensitivity, Self-Efficacy, and Learning Strategy: Mediating and Moderating the Role of Basic Needs Satisfaction
}

\author{
Miki Terada1, Taishi Kawamoto ${ }^{2}$ \\ ${ }^{1}$ Otemae University, Hyogo, Japan \\ ${ }^{2}$ The University of Tokyo, Tokyo, Japan \\ Email: mikiterada.1986@gmail.com
}

How to cite this paper: Terada, M., \& Kawamoto, T. (2017). Rejection Sensitivity, Self-Efficacy, and Learning Strategy: Mediating and Moderating the Role of Basic Needs Satisfaction. Psychology, 8, 449-462. https://doi.org/10.4236/psych.2017.83028

Received: January 26, 2017

Accepted: February 24, 2017

Published: February 27, 2017

Copyright @ 2017 by authors and Scientific Research Publishing Inc. This work is licensed under the Creative Commons Attribution International License (CC BY 4.0).

http://creativecommons.org/licenses/by/4.0/ (c) †) Open Access

\begin{abstract}
Rejection sensitive people often experience interpersonal difficulties, resulting in dissatisfaction with their need for relatedness. However, whether they are satisfied with their autonomy and competence, or experience difficulties from these factors other than in interpersonal relationships, remains largely unexplored. This study examined the influence of rejection sensitivity and need satisfaction (autonomy, competence, and relatedness) on learning strategy and self-efficacy. We found that competence satisfaction mediates the relationship between rejection sensitivity and self-efficacy. In addition, hierarchical regression analysis revealed a significant three-way interaction of rejection sensitivity, autonomy, and competence satisfaction with learning strategy. Competence satisfaction has a positive effect when individuals have low rejection sensitivity and are satisfied with autonomy need, whereas autonomy satisfaction has a positive effect when individuals have high rejection sensitivity and are dissatisfied with their competence levels. This suggests that autonomy and competence satisfaction levels are important for the understanding of psychological difficulties in rejection sensitive individuals.
\end{abstract}

\section{Keywords}

Rejection Sensitivity, Self-Efficacy, Learning Strategy, Autonomy, Competence, Relatedness

\section{Introduction}

Interpersonal relationships and learning are important aspects of school life for university students. People with high rejection sensitivity-characterized as anxious expectation of and defensive reaction to social rejection (Downey \& Feld- 
man, 1996)-tend to experience psychological difficulties. How can they spend their school life successfully, especially in relation to learning? This research approaches how rejection sensitivity is related to learning with need satisfaction. We sought to develop our understanding of the difficulties rejection sensitive individuals have in these situations by focusing on learning strategy and self-efficacy. We focused on the possible mediating roles of need satisfaction on the relationships between rejection sensitivity and learning strategy/self-efficacy. We also investigated the possible moderating role of rejection sensitivity on the relationship between satisfaction of needs and learning strategy/self-efficacy.

\subsection{Learning Strategy, Self-Efficacy, and Rejection Sensitivity}

Recently, problem based learning (PBL) has been adopted by universities. PBL is one of the learning approaches that students use to solve problems and answer questions which are raised or found by themselves. To experience success in PBL, students need to use a learning strategy. A learning strategy is defined as proceeding with conscious study to enhance the learning effects that derive from cognitive, meta-cognitive, and motivational strategies (Dignath, Buettner, \& Langfeld, 2008; Pintrich \& DeGroot, 1990). A learning strategy delivers the large component of self-regulated learning that is necessary for PBL (English \& Kitsantas, 2013). In fact, managing a learning strategy which engages in sustaining motivation, goal setting, strategic planning, maintaining attention on important information related to goals, monitoring progress toward those goals, self-observation, engaging in self-reflection through feedback, and self-motivation, has an important role in the self-regulatory process (Zimmerman, 2013).

In addition to its association with learning strategies, self-efficacy is also an important factor in increasing academic success (Holzberger, Philipp, \& Kunter, 2013; Zimmerman, 2000). For example, Komarraju and Nadler (2013) showed that self-efficacious students can achieve academic success because they monitor and self-regulate their impulses, and persist in the face of difficulties. Another study revealed that self-efficacy beliefs in self-regulated learning better predict future academic achievement beyond the effects of previous achievements, gender, socioeconomic status, intelligence, personality traits, and self-esteem (Zuffianò et al., 2013).

Using a learning strategy and understanding the impact of self-efficacy sometimes requires support from others (Schunk \& Hanson, 1985; Newman, 1990). For intense people, prior studies have suggested that socially shared and regulated learning has an important role in self-regulated learning (Järvelä et al., 2015; Malmberg, Järvelä, Järvenoja, \& Panadero, 2015). Rejection sensitive people, however, may find it difficult to use a learning strategy, or to feel strong selfefficacy, because of their anxious expectations of, and defensive reactions to, social rejection. Past studies have shown that rejection sensitivity leads to negative interpersonal relationships, and a feeling of increased interpersonal distress (Downey \& Feldman 1996; Feldman \& Downey, 1994; Romero-Canyas \& Downey, 2005). 
Although few studies have investigated the relationship between rejection sensitivity and learning strategy or self-efficacy, there is some indirect evidence that rejection sensitivity has an influence on learning strategy and self-efficacy. For example, Downey, Lebolt, Rincon, \& Freitas (1998) found a relationship between rejection sensitivity and a decline in children's academic performance. Another study showed that rejection sensitivity was negativity associated with cognitive function, including logical reasoning and nonverbal intelligence (Tobia, Riva, \& Caprin, 2016). Thus, we predict that rejection sensitivity is negatively associated with learning strategy and self-efficacy.

\subsection{Mediating Roles of Need Satisfaction between Rejection Sensitivity and Learning Strategy/Self-Efficacy}

Self-determination theory (SDT) shows that needs have been defined in the areas of autonomy, competence and relatedness (Deci \& Ryan, 1987, 2000). These needs are naturally provided for in basic needs, and the fulfillment of these needs produces a positive effect on study, life satisfaction, and mental health (Gunnell, Crocker, Mack, Wilson, \& Zumbo, 2014; Ng et al., 2012; Ryan, Huta, \& Deci, 2008; Silva et al., 2010). Thus, in this study we focus on the satisfaction of needs as a possible mediator between rejection sensitivity and learning strategy/self-efficacy.

How is rejection sensitivity associated with the satisfaction of each need? Rejection sensitivity is negatively associated with interpersonal competence and the ability to initiate new relationships (Butler, Doherty, \& Potter, 2007). Rejection sensitivity is also associated with lack of self-worth in the area of perceived competence (Ayduk et al., 2000). It can be surmised then that rejection sensitive people may not have enough competence beyond domains for use in learning strategies and self-efficacy. They also may not have enough autonomy, because people with a high level of rejection sensitivity report higher self-silencing behaviors (Harper, Dickson, \& Welsh, 2006). Harper et al. (2006) showed that selfsilencing behaviors lead to the suppression of personal voices and opinions to maintain/protect intimate relationships. This helps to maintain relationships, and may be reinforced for individuals who possess anxious or angry expectations in relation to rejection. In addition, past research has shown that rejection sensitive people have poor satisfaction levels, especially with regard to relatedness need, because it is difficult for them to have enough relationships to offset this (Zimmer-Gembeck, Trevaskis, Nesdale, \& Downey, 2014). Downey and Feldman (1996) provide evidence that people who are highly sensitive to rejection are more likely to misperceive ambiguous behavior, and are more dissatisfied with their romantic relationships. We can therefore assume that rejection sensitivity cannot be satisfied by relatedness, and, people with high rejection sensitivity may reduce the effectiveness of their learning strategies and self-efficacy because they are not satisfied with autonomy, competence, and relatedness. Thus, we predict that satisfaction of needs mediates the relationships between rejection sensitivity and learning strategy/self-efficacy. 


\subsection{The Moderating Role of Rejection Sensitivity on the Relationship between Needs Satisfaction and Learning Strategy/Self-Efficacy}

In addition to the possibility that satisfaction of needs mediates in the relationship between rejection sensitivity and learning strategy/self-efficacy, rejection sensitivity has a moderating role on the relationships between satisfaction of needs and learning strategy/self-efficacy. In other words, the influence of rejection sensitivity and satisfaction of needs on learning strategy and self-efficacy may be more complex than hitherto thought.

One possibility is that positive impacts from the satisfaction of autonomy and competence needs on learning strategy and self-efficacy only occur in people with low rejection sensitivity. Prior studies have suggested that a good balance of satisfaction across the three needs has an effect on happiness and well-being, rather than this being a simple sum of the three needs (Sheldon \& Niemiec, 2006). For example, someone that tries to facilitate their own psychological health may have a higher level of satisfaction in relation to their need for autonomy, competence, and relatedness than someone having greater autonomy and competence who may feel a low level of satisfaction in regard to their need for relatedness, even though both experience the same total amount of satisfaction. Rejection sensitive individuals, therefore, may be falling into a state of imbalance even if they have enough autonomy and competence, because they are not fulfilled at the level of relatedness satisfaction. There may in fact be a positive impact from the satisfaction of autonomy and competence needs on learning strategy/selfefficacy in people with a low sensitivity to rejection, but not in people having high rejection sensitivity. Thus, we predict that the positive effect of autonomy and competence satisfaction of needs on learning strategy/self-efficacy is moderated by rejection sensitivity.

Another possibility is that the satisfaction of competence needs will have harmful effects on people with high rejection sensitivity. Self-verification theory (Swann \& Read, 1981), holds that people want to confirm themselves correctly, and to think that their way of thinking and values are not wrong. Through such processes, people create a social reality and sustain their conceptions. Here, rejection sensitivity is associated with lack of interpersonal competence (Butler et al., 2007), and self-worth with perceived competence (Ayduk et al., 2000). Thus, if people with high rejection sensitivity are satisfied with their competence levels, this will be inconsistent with their self-view. We therefore predict that high competence levels will be harmful for people with high rejection sensitivity, because it is difficult for them to confirm themselves. In contrast, they could use more learning strategies, and have high self-efficacy with low competence rather than high competence, because it is easy for people with rejection sensitivity to consistently believe that they have low task competence.

Also, it is a possibility that high autonomy could be a cause for conflict for people with high rejection sensitivity. Harper et al. (2006) showed that self-silencing behaviors help to maintain a relationship, and may be reinforced in in- 
dividuals who possess anxious or angry expectations of rejection. They also considered the conflict over how the expression of false self-versus-true self contributes to the onset of depression. Therefore, we examine how rejection sensitive people can use more learning strategies, and experience high self-efficacy with low autonomy, rather than high autonomy.

\subsection{The Present Research}

We sought to investigate the influence of rejection sensitivity and the satisfaction of needs on learning strategy/self-efficacy. More specifically, we tested whether 1) need satisfaction mediates the relationship between rejection sensitivity and learning strategy/self-efficacy, and 2) whether rejection sensitivity moderates the relationship between need satisfaction and learning strategy/self-efficacy.

\section{Method}

\subsection{Participants}

A web survey was conducted by a polling organization company (Fastask). The questionnaire was randomly distributed to 309 male and female from 15 to 24 years old on the web monitors. At the beginning of the questionnaire, "What your university grade? $-1.1^{\text {st }}, 2.2^{\text {nd }}, 3.3^{\text {rd }}, 4.4^{\text {th }}, 5$. Other" was asked. And, respondents who selected other than 5 and did not have a defect such as unanswered data were selected. Finally, data were collected from 179 university students (82 females, $M_{\text {age }}=20.00, S D=1.42$ ).

\subsection{Measures}

Learning strategy. Learning strategies were measured via their cognitive aspects (Ito, 1996; Pintrich \& De Groot, 1990), their meta-cognitive aspects (Ichihara \& Arai, 2006), and self-motivational strategy scales (Ito \& Shinto, 2003) that included 23 items $(\alpha=.87)$. These items have been used in previous studies (Jones, Estell, \& Alexander, 2008; Loyens, Rikers, \& Schmidt, 2008). Participants were asked to rate how often they use learning strategies using a 5-point scale ranging from 1 (Not apply) to 5 (Apply), and averages derived. The average scores were analyzed in the present study.

Self-efficacy. We used The General Self-Efficacy Scale (GSES; Sakano \& Tohjoh, 1986; Bandura, 1977). The GSES contains 16 items that measure individual strength of general self-efficacy across a variety of settings in everyday life $(\alpha=.64)$. Participants were asked whether these items did or did not apply in their situation. The total score relating to high self-efficacy was used in the analysis (range: 0 - 12).

Rejection sensitivity. We used the 9-situation Adult Rejection Sensitivity Questionnaire (Berenson, Gyurak, Ayduk, Downey, Garner, Mogg, \& Pine, 2009) to measure rejection sensitivity ( $\alpha=.73$ ). For each situation, participants rated the level of anxiety or concern that they would experience about the outcome of a situation, using a 6-point scale ranging from 1 (Very unconcerned) to 6 (Very concerned). Participants also rated the likelihood that an interaction partner 
would respond in an accepting manner, again using a 6-point scale ranging from 1 (Very unlikely) to 6 (Very likely). A cross-situational total RSQ score was computed by obtaining the mean scores across the situations described in the questionnaire, as was done in previous studies (Berenson et al., 2009; Kawamoto, Ura, \& Hiraki, 2017).

Need satisfactions. Need satisfaction was measured using the Basic Psychological Needs Scale for School Life (BPNS-SL; Nishimura, \& Sakurai, 2015; Ryan \& Deci, 2000). This scale consists of 12 items each including 4 items. Autonomy and relatedness included 1 reversal item. We calculated the a coefficients by scoring each item respectively, excluding the 1 reversal item, because this item reduced the a coefficients, autonomy ( $\alpha=.73)$, competence $(\alpha=.80)$, and relatedness $(\alpha=.75)$. Participants reported the degree to which each statement applied to themselves, using a 4-point scale ranging from 1 (not at all) to 4 (applies very well). The average score was used in the present study.

Learning time outside the classroom. We asked how much time was spent on learning (e.g., homework, reports) outside of classroom per day. This was categorized as 1: not at all, 2: less than 30 minutes, 3: from 30 minutes to less than 1 hour, 4: from 1 hour to less than 2 hours, 5: from 2 hours to less than 3 hours, 6: from 3 hours to less than 4 hours, and 7: more than 4 hours.

\subsection{Data Analysis}

First, we conducted a correlational analyses to confirm the relationships among variables. Next, we performed a mediation analysis to test for a possible mediating effect of need satisfaction on the relationship between rejection sensitivity, the use of learning strategies, and self-efficacy. We applied the bootstrapping method (1000 resamples) using the PROCESS macro (Hayes, 2015). Finally, hierarchical regression analysis was conducted to examine the possible moderating role of rejection sensitivity on the relationships between needs satisfaction, the use of learning strategies, and self-efficacy (Shimizu, 2016).

\section{Results}

\subsection{Correlation of Family Support, Psychopathy, and the Amount of Punishment}

As shown in Table 1, although rejection sensitivity was negatively correlated with self-efficacy, rejection sensitivity was not significantly associated with learning strategy. In addition, rejection sensitivity was negatively correlated with satisfaction of the three needs. Finally, both learning strategy and self-efficacy were positively correlated with satisfaction of the three needs.

\subsection{The Mediating Role of Needs Satisfaction between Rejection Sensitivity and Learning Strategy/Self-Efficacy}

As can be seen in Figure 1, after having introduced sex, age, grade, and learning time outside the classroom as covariates, the analysis revealed significant partial mediation effects from the satisfaction of needs on the link between rejection 
Table 1. Descriptive statistics and correlation among variables.

\begin{tabular}{|c|c|c|c|c|c|c|c|c|c|c|c|c|c|}
\hline & & 1 & & 2 & & 3 & & 4.1 & & 4.2 & & 4.3 & 5 \\
\hline 1. & Learning strategy & - & & & & & & & & & & & \\
\hline 2. & Self-efficacy & .162 & * & - & & & & & & & & & \\
\hline 3. & RS & -.049 & & -.354 & ** & - & & & & & & & \\
\hline 4.1. & Autonomy & .174 & $* *$ & .346 & ** & -.251 & $* *$ & - & & & & & \\
\hline 4.2 . & Competence & .203 & $* *$ & .393 & ** & -.231 & $* *$ & .651 & $* *$ & - & & & \\
\hline 4.3. & Relatedness & .250 & $* *$ & .234 & ** & -.227 & $* *$ & .432 & $* *$ & .417 & ** & - & \\
\hline \multirow[t]{3}{*}{5.} & Learning time & .260 & $* *$ & -.033 & & .096 & & .042 & & .084 & & .059 & - \\
\hline & Mean & 3.30 & & 6.99 & & 11.82 & & 2.72 & & 2.53 & & 2.63 & 3.47 \\
\hline & $S D$ & 0.58 & & 3.11 & & 3.72 & & 0.72 & & 0.73 & & 0.75 & 1.67 \\
\hline
\end{tabular}

Note: RS $=$ Rejection sensitivity. ${ }^{*} p<.05 .{ }^{* *} p<.01$.

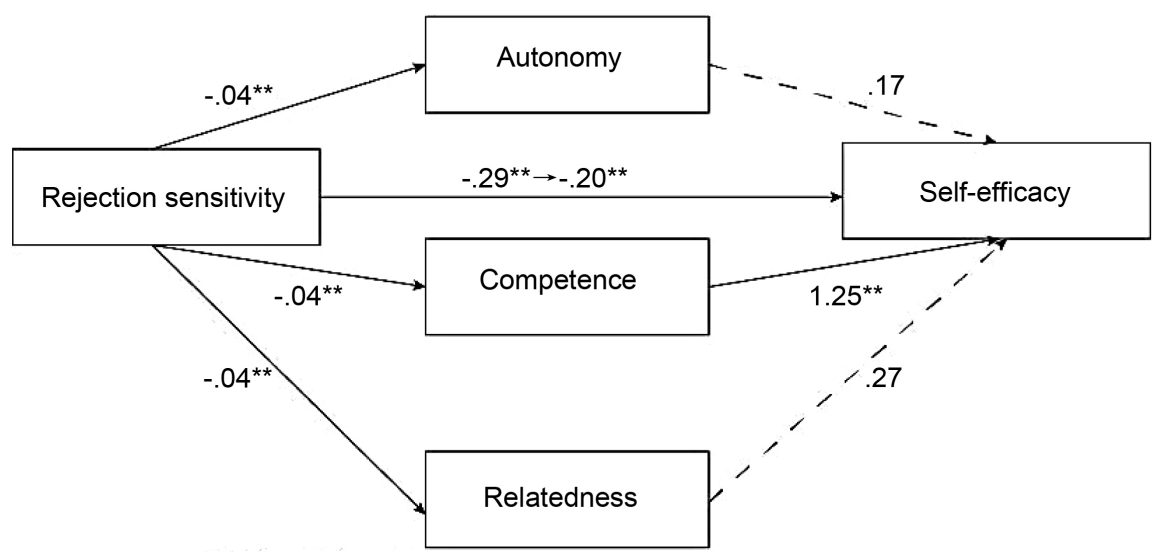

Figure 1. The mediation effect of the satisfaction of needs on the relationship between rejection sensitivity and self-efficacy. Note. ${ }^{\star} p<.05 .{ }^{* *} p<.01$.

sensitivity and self-efficacy (indirect effect $=-.079,95 \% \mathrm{CI}[-.161,-.025]$ ). In addition, although the simple indirect effects of competence satisfaction (indirect effect $=-.058,95 \% \mathrm{CI}[-.130,-.014])$ were significant, those of autonomy (indirect effect $=-.008,95 \% \mathrm{CI}[-.058, .029])$ and relatedness satisfaction (indirect effect $=-.012,95 \% \mathrm{CI}[-.055, .012]$ ) were not. Finally, because there was no significant correlation between rejection sensitivity and learning strategy, we did not conduct a mediation analysis in respect of learning strategy.

\subsection{The Moderating Role of Rejection Sensitivity between Needs Satisfaction and Learning Strategy/Self-Efficacy}

Hierarchical regression analysis revealed a significant three-way interaction between the effects of rejection sensitivity, autonomy satisfaction, and competence satisfaction on learning strategy (Table 2, Figure 2). Simple slope analysis indicated that the effect of competence satisfaction on learning strategy appeared when people have low rejection sensitivity and high autonomy $(b=.23, p=.06)$. When people have low rejection sensitivity and low autonomy $(b=.09, p=.46)$, high rejection sensitivity and low autonomy $(b=.14, p=.19)$, and high rejection 
Table 2. The result of hierarchical regression analysis.

\begin{tabular}{|c|c|c|c|c|c|c|c|c|c|c|c|c|c|c|c|c|}
\hline & \multicolumn{8}{|c|}{ Learning strategy } & \multicolumn{8}{|c|}{ Self-efficacy } \\
\hline & Step1 & & Step2 & & Step3 & & Step4 & & Step1 & & Step2 & & Step3 & & Step4 & \\
\hline Intercept & 3.284 & $* *$ & 3.283 & $* *$ & 3.307 & $* *$ & 3.304 & $* *$ & 7.136 & ** & 7.123 & $* *$ & 7.299 & $* *$ & 7.296 & ** \\
\hline Sex & 0.214 & * & 0.225 & $* *$ & 0.226 & $* *$ & 0.260 & $* *$ & -0.854 & + & -0.700 & & -0.612 & & -0.573 & \\
\hline Age & 0.044 & & 0.061 & & 0.054 & & 0.051 & & -0.298 & & -0.068 & & -0.025 & & -0.028 & \\
\hline Grade & -0.016 & & -0.031 & & -0.025 & & -0.018 & & 0.327 & & 0.119 & & 0.063 & & 0.071 & \\
\hline Learning time & 0.114 & $* *$ & 0.114 & $* *$ & 0.114 & $* *$ & 0.106 & $* *$ & -0.111 & & -0.089 & & -0.096 & & -0.105 & \\
\hline Autonomy & & & 0.045 & & 0.039 & & 0.033 & & & & 0.249 & & 0.161 & & 0.154 & \\
\hline Competence & & & 0.104 & & 0.097 & & 0.074 & & & & 1.317 & $* *$ & 1.289 & $* *$ & 1.262 & ** \\
\hline RS & & & -0.008 & & -0.006 & & 0.004 & & & & -0.215 & ** & -0.201 & ** & -0.190 & ** \\
\hline Autonomy ${ }^{\star}$ Competence & & & & & -0.051 & & -0.066 & & & & & & -0.352 & & -0.369 & \\
\hline $\mathrm{RS}^{*}$ Autonomy & & & & & 0.025 & & 0.009 & & & & & & -0.070 & & -0.089 & \\
\hline $\mathrm{RS}^{\star}$ Competence & & & & & -0.014 & & -0.024 & & & & & & 0.160 & & 0.148 & \\
\hline $\begin{array}{c}\mathrm{RS}^{\star} \text { Autonomy }{ }^{\star} \text { Competenc } \\
\mathrm{e}\end{array}$ & & & & & & & -0.044 & * & & & & & & & -0.051 & \\
\hline$R^{2}$ & .126 & $* *$ & .161 & $* *$ & .172 & $* *$ & .199 & $* *$ & .026 & & .250 & $* *$ & .268 & $* *$ & .269 & ** \\
\hline$\Delta R^{2}$ & & & .036 & + & .010 & & .027 & $* *$ & & & .224 & $* *$ & .018 & & .001 & \\
\hline
\end{tabular}

Note: RS $=$ Rejection sensitivity. ${ }^{+} p<.10 .{ }^{*} p<.05 .{ }^{* *} p<.01$.

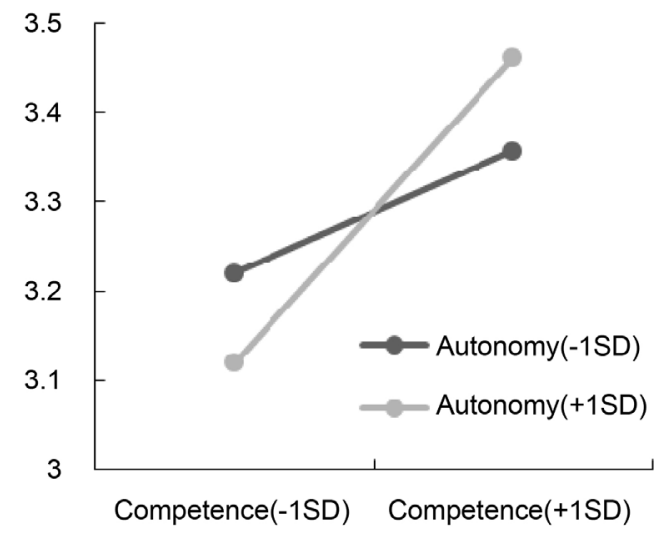

(a)

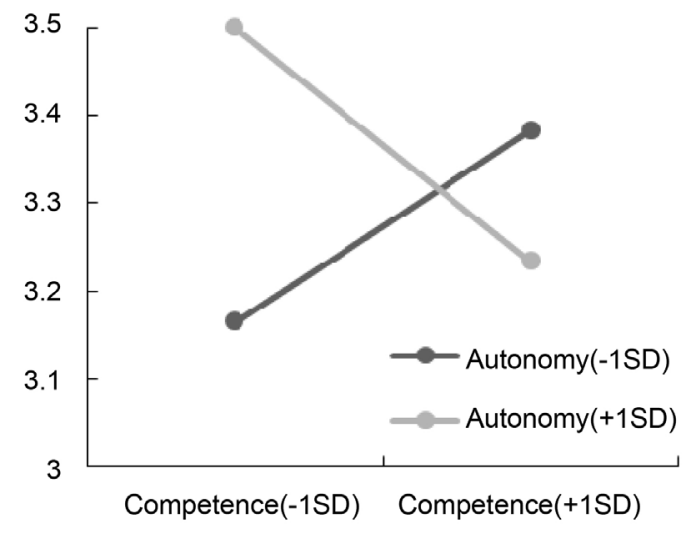

(b)

Figure 2. The modulation effect of rejection sensitivity on the relationship between satisfaction of needs and learning strategies, and (a) low rejection sensitivity, and (b) high rejection sensitivity.

sensitivity and high autonomy $(b=-.18, p=.21)$, the effect of competence satisfaction on learning strategy did not appear. These results partly support our expectation, and indicate that the impact of competence satisfaction is seen only in conditions of high autonomy and low rejection sensitivity. In other words, the synergy effect of autonomy and competence satisfaction on learning strategy is shown only in people with low rejection sensitivity.

In addition, and contrary to our expectations, the effect of satisfaction with autonomy did not appear when people have low rejection sensitivity and high levels of competence $(b=.07, p=.60)$, whereas it was significant when people have high rejection sensitivity and low levels of competence $(b=.23, p=.05)$. 
When people have low rejection sensitivity and low levels of satisfaction with their competence $(b=-.07, p=.53)$, and high rejection sensitivity and high autonomy $(b=-.10, p=.50)$, the effect of satisfaction with level of competence on learning strategy does not appear. It should be noted however, that a significant effect of satisfaction with autonomy is seen when people have high rejection sensitivity and low competence levels. In other words, people who have high rejection sensitivity use learning strategies more when they feel their competence level is low than when their competence level is high. There were no significant interactions between the effects of rejection sensitivity, and satisfaction with autonomy and competence on self-efficacy (Table 2).

\section{Discussion}

The purpose of this study was to examine the influence of rejection sensitivity and the satisfaction of needs on learning strategy/self-efficacy. More specifically, we examined, 1) the mediating roles of need satisfaction on the relationships between rejection sensitivity and learning strategy/self-efficacy, and 2) the moderating role of rejection sensitivity on the relationship between satisfaction of needs and learning strategy/self-efficacy. We found that satisfaction with competence level mediates the relationship between rejection sensitivity and self-efficacy. In addition, rejection sensitivity moderates the relationships between satisfaction of needs and learning strategy. The synergistic effect of autonomy and satisfaction with level of competence on learning strategy appeared only in people with low rejection sensitivity. People who have high rejection sensitivity and high autonomy use more learning strategies when they have low competence levels than when their competence levels are high.

These findings extend our understanding of the relationships between trait rejection sensitivity and self-efficacy, by showing that competence mediates these relationships. Prior studies have revealed the association between rejection sensitivity and cognitive functioning, as well as with academic success (Downey et al., 1998). We therefore suggest that rejection sensitivity will result in decreased self-efficacy through a lack of satisfaction of the competence need. Unexpectedly however, even though rejection sensitive individuals are not fulfilled when they are satisfied with relatedness, this form of satisfaction did not mediate the relationship between rejection sensitivity and self-efficacy. In this study, we showed that it is not only relatedness that is important; people with high rejection sensitivity have greater levels of depleted competence satisfaction, which does lead to a lack of self-efficacy.

Our findings offer new insights from rejection sensitivity research by indicating that rejection sensitivity modulates the effect relationships between needs satisfaction and learning strategies. First, the positive effects of competence on learning strategy appears only with high autonomy and low rejection sensitivity. Prior studies have revealed that a good balance of satisfaction of the three needs has a greater impact on happiness and well-being than a simple sum of satisfaction in relation to the three needs (Sheldon \& Niemiec, 2006). Our results sup- 
port this finding. The synergistic effect of satisfaction with autonomy and competence levels on learning strategies appeared only when a good balance between satisfaction and relatedness was experienced. Second, people with high rejection sensitivity and high autonomy more often use more learning strategies if they have low competence levels than if they have high competence levels. In other words, learning strategies are harmful to satisfaction with competence level needs for rejection sensitive individuals, whereas they facilitate learning strategies in people with low competence levels. Self-verification theory (Swann \& Read, 1981) suggests that people want to confirm themselves correctly, and to think that their way of thinking and values are not wrong. Our results support this. People with high rejection sensitivity use more learning strategies when they have low competence levels, because it is harmful to have a high competence level as this would not be consistent with their self-worth.

We propose two educational suggestions from these findings: First, fostering autonomy is an important way for rejection sensitive people to avoid rejection and preserve relationships. Only people who have a low level of rejection sensitivity expect acceptance, or engage higher-level cognitive self-regulatory systems (Romero-Canyas \& Downey, 2013). Although people who have high level of rejection sensitivity tend to behave in a more self-silencing way, it is necessary to experience interpersonal relationships to enhance autonomy choice. Enhancing autonomy choice or asserting themselves properly will have a positive impact, on not only interpersonal relationships, but also on learning, especially for rejection sensitive people; second, in relation to competence, rejection sensitive people use learning strategies more often when they have low competence levels, than when they have high competence levels. These findings emphasize the importance of understanding the cognitive imbalances and conflicts rejection sensitive people may have. It is worthwhile for them to interact proactively with someone, and grow competence through accomplishment. But for rejection sensitive people, interacting proactively with someone else is difficult, so it may be necessary to start by changing self-worth.

Unexpectedly, however, the satisfaction of needs has different mediating and moderating roles on self-efficacy and learning strategies. First, rejection sensitivity has no correlation with learning strategy. The reason why learning strategies are used, even though they have an important role in increasing academic success as well as in self-efficacy, is that they play different roles in the self-regulatory process (Zimmerman, 2000; Zimmerman \& Martinez-Pons, 1990). Learning strategy mainly carries a cognitive aspect, but self-efficacy mainly carries a motivational aspect. Both play a complementary role in self-regulated learning. Second, the study results show no significant interaction between rejection sensitivity, and satisfaction with autonomy and competence levels on self-efficacy. Sheldon and Niemiec (2006) proposed that imbalances in the satisfaction of needs reflects chronic stress and role conflict. Also, harmonious passions are more salubrious than obsessive passions (Vallerand et al., 2003). If people with high levels of rejection sensitivity are highly competent, they will fall into im- 
balance, which in some will be obsessive, and will decrease the use of learning strategies. In contrast, when they have low competence levels, they will use learning strategies with harmonious passion. But the imbalance in rejection sensitivity and high competence may not make for obsessive behavior for self-efficacy purposes.

We acknowledge the several limitations of this study. First, the possibility remains that people who often use learning strategies, and have efficient self-efficacy, tend to have a low level of rejection sensitivity. There is thus benefit from longitudinal research designs that enable identification of the potential casual relationships between rejection sensitivity and learning strategy/self-efficacy. Second, although we investigated learning strategy and self-efficacy, the effect of learning should be verified by examining a greater range of indicators. Future research focusing on achievement performance and task deadline expectations would improve our understanding of the relationship between rejection sensitivity and learning.

\section{Conclusion}

To conclude, the present research showed how rejection sensitive people tend to experience psychological difficulties in trying to spend their school life successfully, especially in relation to learning. Recently, learning strategy use themselves and socially shared learning has been prompted in university. It is said that exiting lesson would be innovative for students. Of course, there are effective prospect for students. This study serves to highlights and we suggest that autonomy and satisfaction with competence levels are important when we are trying to understand the psychological difficulties faced by rejection sensitive individuals.

\section{References}

Ayduk, O., Mendoza-Denton, R., Mischel, W., Downey, G., Peake, P. K., \& Rodriguez, M. (2000). Regulating the Interpersonal Self: Strategic Self-Regulation for Coping with Rejection Sensitivity. Journal of Personality and Social Psychology, 79, 776-792. https://doi.org/10.1037/0022-3514.79.5.776

Bandura, A. (1977). Self-Efficacy: Toward a Unifying Theory of Behavioral Change. Psychological Review, 84, 191-215. https://doi.org/10.1037/0033-295X.84.2.191

Berenson, K. R., Gyurak, A., Ayduk, O., Downey, G., Garner, M. J., Mogg, K., \& Pine, D. S. (2009). Rejection Sensitivity and Disruption of Attention by Social Threat Cues. Journal of Research in Personality, 43, 1064-1072. https://doi.org/10.1016/j.jrp.2009.07.007

Butler, J. C., Doherty, M. S., \& Potter, R.M. (2007). Social Antecedents and Consequences of Interpersonal Rejection Sensitivity. Personality and Individual Differences, 43, 13761385. https://doi.org/10.1016/j.paid.2007.04.006

Deci, E. L., \& Ryan, R. M. (1987). The Support of Autonomy and the Control of Behavior. Journal of Personality and Social Psychology, 53, 1024-1037.

https://doi.org/10.1037/0022-3514.53.6.1024

Deci, E. L., \& Ryan, R. M. (2000). The "What" and "Why" of Goal Pursuits: Human Needs and the Self-Determination of Behavior. Psychological Inquiry, 11, 227-268.

https://doi.org/10.1207/S15327965PLI1104_01 
Dignath, C., Buttner, G., \& Langfeld, H. P. (2008). How Can Primary School Students Learn Self-Regulated Learning Strategies Most Effectively? A Meta-Analysis on SelfRegulation Training Programmes. Educational Research Review, 3, 101-129. https://doi.org/10.1016/j.edurev.2008.02.003

Downey, G., \& Feldman, S. I. (1996). Implications of Rejection Sensitivity for Intimate Relationships. Journal of Personality and Social Psychology, 70, 1327-1343. https://doi.org/10.1037/0022-3514.70.6.1327

Downey, G., Lebolt, A., Rincón, C., \& Freitas, A. L. (1998). Rejection Sensitivity and Children's Interpersonal Difficulties. Child Development, 69, 1074-1091. https://doi.org/10.1111/j.1467-8624.1998.tb06161.x

English, M. C., \& Kitsantas, A. (2013). Supporting Student Self-Regulated Learning in Problem-and Project-Based Learning. Interdisciplinary Journal of Problem-Based Learning, 7, 128-150. https://doi.org/10.7771/1541-5015.1339

Feldman, S., \& Downey, G. (1994). Rejection Sensitivity as a Mediator of the Impact of Childhood Exposure to Family Violence on Adult Attachment Behavior. Development and Psychopathology, 6, 231-247. https://doi.org/10.1017/S0954579400005976

Gunnell, K. E., Crocker, P. R., Mack, D. E., Wilson, P. M., \& Zumbo, B. D. (2014). Goal Contents, Motivation, Psychological Need Satisfaction, Well-Being and Physical Activity: A Test of Self-Determination Theory over 6 Months. Psychology of Sport and EXercise, 15, 19-29. https://doi.org/10.1016/j.psychsport.2013.08.005

Harper, M. S., Dickson, J. W., \& Welsh, D. P. (2006). Self-Silencing and Rejection Sensitivity in Adolescent Romantic Relationships. Journal of Youth and Adolescence, 35, 435-443. https://doi.org/10.1007/s10964-006-9048-3

Hayes, A. F. (2015). An Index and Test of Linear Moderated Mediation. Multivariate Behavioral Research, 50, 1-22. https://doi.org/10.1080/00273171.2014.962683

Holzberger, D., Philipp, A., \& Kunter, M. (2013). How Teachers' Self-Efficacy Is Related to Instructional Quality: A Longitudinal Analysis. Journal of Educational Psychology, 105, 774-786. https://doi.org/10.1037/a0032198

Ichihara, M., \& Arai, K. (2006). Moderator Effects of Meta-Cognition: A Test in Math of a Motivational Model. The Japanese Journal of Educational Psychology, 54, 199-210. https://doi.org/10.5926/jjep1953.54.2_199

Ito, T. (1996). Self-Efficacy, Causal Attribution and Learning Strategy in an Academic Achievement Situation. The Japanese Journal of Educational Psychology, 44, 340-349. https://doi.org/10.5926/jjep1953.44.3_340

Ito, T., \& Shinto, T. (2003). Construction of the Self-Motivational Strategies Scale for Junior High School Students. The Japanese Journal of Psychology, 74, 209-217. https://doi.org/10.4992/jjpsy.74.209

Järvelä, S., Kirschner, P. A., Panadero, E., Malmberg, J., Phielix, C., Jaspers, J., Koivuniemi, M., \& Järvenoja, H. (2015). Enhancing Socially Shared Regulation in Collaborative Learning Groups: Designing for CSCL Regulation Tools. Educational Technology Research and Development, 63, 125-142. https://doi.org/10.1007/s11423-014-9358-1

Jones, M. H., Estell, D. B., \& Alexander, J. M. (2008). Friends, Classmates, and Self-Regulated Learning: Discussions with Peers inside and outside the Classroom. Metacognition and Learning, 3, 1-15. https://doi.org/10.1007/s11409-007-9007-8

Kawamoto, T., Ura, M., \& Hiraki, K. (2017). Curious People Are less Affected by Social Rejection. Personality and Individual Differences, 105, 264-267.

https://doi.org/10.1016/j.paid.2016.10.006

Komarraju, M., \& Nadler, D. (2013). Self-Efficacy and Academic Achievement: WHY DO 
Implicit Beliefs, Goals, and Effort Regulation Matter? Learning and Individual Differences, 25, 67-72. https://doi.org/10.1016/j.lindif.2013.01.005

Loyens, S. M. M., Rikers, R. M. J. P., \& Schmidt, H. G. (2008). Relationships between Students' Conceptions of Constructivist Learning and Their Regulation and Processing Strategies. Instructional Science, 36, 445-462. https://doi.org/10.1007/s11251-008-9065-6

Malmberg, J., Järvelä, S., Järvenoja, H., \& Panadero, E. (2015). Promoting Socially Shared Regulation of Learning in CSCL: Progress of Socially Shared Regulation among Highand Low-Performing Groups. Computers in Human Behavior, 52, 562-572. https://doi.org/10.1016/j.chb.2015.03.082

Newman, R. S. (1990). Children's Help-Seeking in the Classroom: The Role of Motivational Factors and Attitudes. Journal of Educational Psychology, 82, 71-80. https://doi.org/10.1037/0022-0663.82.1.71

Ng, J. Y., Ntoumanis, N., Thøgersen-Ntoumani, C., Deci, E. L., Ryan, R. M., Duda, J. L., \& Williams, G. C. (2012). Self-Determination Theory Applied to Health Contexts a Meta-Analysis. Perspectives on Psychological Science, 7, 325-340. https://doi.org/10.1177/1745691612447309

Nishimura, T., \& Sakurai, S. (2015). Relationship between Basic Psychological Needs and School Morale in Junior High School Students: Development of the Basic Psychological Needs Scale for School Life. The Japanese Journal of Personality, 24, 124-136. https://doi.org/10.2132/personality.24.124

Pintrich, P. R., \& De Groot, E. V. (1990). Motivational and Self-Regulated Learning Components of Classroom Academic Performance. Journal of Educational Psychology, 82, 33-40. https://doi.org/10.1037/0022-0663.82.1.33

Romero-Canyas, R., \& Downey, G. (2013). What I See When I Think It's about Me: People Low in Rejection-Sensitivity Downplay Cues of Rejection in Self-Relevant Interpersonal Situations. Emotion, 13, 104-117. https://doi.org/10.1037/a0029786

Ryan, R. M., \& Deci, E. L. (2000). The Basic Need Satisfaction in Life Scale. Unpublished Manuscript, Rochester, NY: University of Rochester.

Ryan, R. M., Huta, V., \& Deci, E. L. (2008). Living Well: A Self-Determination Theory Perspective on Eudaimonia. Journal of Happiness Studies, 9, 139-170. https://doi.org/10.1007/s10902-006-9023-4

Sakano, Y., \& Tohjoh, M. (1986). The General Self-Efficacy Scale (GSES): Scale Development and Validation. Japanese Journal of Behavior Therapy, 12, 73-82.

Schunk, D. H., \& Hanson, A. R. (1985). Peer Models: Influence on Children's Self-Efficacy and Achievement. Journal of Educational Psychology, 77, 313-322. https://doi.org/10.1037/0022-0663.77.3.313

Sheldon, K. M., \& Niemiec, C. P. (2006). It's Not Just the Amount That Counts: Balanced Need Satisfaction Also Affects Well-Being. Journal of Personality and Social Psychology, 91, 331-341. https://doi.org/10.1037/0022-3514.91.2.331

Shimizu, H. (2016). An Introduction to the Statistical Free Software HAD: Suggestions to Improve Teaching, Learning and Practice Data Analysis. Journal of Media, Information and Communication, 1, 59-73.

Silva, M. N., Vieira, P. N., Coutinho, S. R., Minderico, C. S., Matos, M. G., Sardinha, L. B., \& Teixeira, P. J. (2010). Using Self-Determination Theory to Promote Physical Activity and Weight Control: A Randomized Controlled Trial in Women. Journal of behavioral medicine, 33, 110-122. https://doi.org/10.1007/s10865-009-9239-y

Swann, W. B., \& Read, S. J. (1981). Self-Verification Processes: How We Sustain Our Self-Conceptions. Journal of Experimental Social Psychology, 17, 351-372. 
https://doi.org/10.1016/0022-1031(81)90043-3

Tobia, V., Riva, P., \& Caprin, C. (2016). Who Are the Children Most Vulnerable to Social Exclusion? The Moderating Role of Self-Esteem, Popularity, and Nonverbal Intelligence on Cognitive Performance Following Social Exclusion. Journal of Abnormal Child Psychology, 1-13.

Vallerand, R. J., Blanchard, C., Mageau, G. A., Koestner, R., Ratelle, C., Leonard, M. et al. (2003). Les Passions de l'ame: On Obsessive and Harmonious Passion. Journal of Personality and Social Psychology, 85, 756-767.

https://doi.org/10.1037/0022-3514.85.4.756

Zimmer-Gembeck, M. J., Trevaskis, S., Nesdale, D., \& Downey, G. A. (2014). Relational Victimization, Loneliness and Depressive Symptoms: Indirect Associations via Self and Peer Reports of Rejection Sensitivity. Journal of youth and adolescence, 43, 568-582. https://doi.org/10.1007/s10964-013-9993-6

Zimmerman, B. J. (2000). Self-Efficacy: An Essential Motive to Learn. Contemporary Educational Psychology, 25, 82-91. https://doi.org/10.1006/ceps.1999.1016

Zimmerman, B. J. (2013). From Cognitive Modeling to Self-Regulation: A Social Cognitive Career Path. Educational Psychologist, 48, 135-147.

https://doi.org/10.1080/00461520.2013.794676

Zimmerman, B. J., \& Martinez-Pons, M. (1990). Student 1 Differences in Self-Regulated Learning: Relating Grade, Sex, and Giftedness to self-Efficacy and Strategy Use. Journal of Educational Psychology, 82, 51-59. https://doi.org/10.1037/0022-0663.82.1.51

Zuffianò, A., Alessandri, G., Gerbino, M., Kanacri, B. P. L., Di Giunta, L., Milioni, M., \& Caprara, G. V. (2013). Academic Achievement: The Unique Contribution of Self-Efficacy Beliefs in Self-Regulated Learning beyond Intelligence, Personality Traits, and Self-Esteem. Learning and Individual Differences, 23, 158-162.

https://doi.org/10.1016/j.lindif.2012.07.010

\section{Submit or recommend next manuscript to SCIRP and we will provide best service for you:}

Accepting pre-submission inquiries through Email, Facebook, LinkedIn, Twitter, etc. A wide selection of journals (inclusive of 9 subjects, more than 200 journals)

Providing 24-hour high-quality service

User-friendly online submission system

Fair and swift peer-review system

Efficient typesetting and proofreading procedure

Display of the result of downloads and visits, as well as the number of cited articles

Maximum dissemination of your research work

Submit your manuscript at: http://papersubmission.scirp.org/

Or contact psych@scirp.org 